\title{
BIOSORPTION OF NICKEL (II) ION FROM SYNTHETIC WASTEWATER ON WATERMELON RIND ACTIVATED CARBON USING RESPONSE SURFACE METHODOLOGY (RSM) OPTIMIZATION APPROACH
}

\author{
K. M. Oghenejoboh* \\ Dept of Chemical Engineering, Delta State Univ., P. M. B. 22, Oleh Campus, Oleh-Delta State, Nigeria \\ E-mail addresses: kmoghene@yahoo.com
}

\begin{abstract}
The introduction of lethal heavy metals into the environment from industrial wastes is a major problem that needs immediate attention. In the present study the adsorption efficiency of nickel ions from a synthetic wastewater using watermelon rind activated carbon as a biosorbent is reported. Four basic process variables - initial $\mathrm{Ni}^{2+}$ concentration (5 - 100mg/1); $p H$ ( 2 - 7); contact time (20 - 720 minutes) and adsorbent dosage (5 - 25g/I) were used for the investigation. Response surface (Box Behnken design expert 7.0®) methodology based on a design of experiment (DOE) that produced 29 batch experimental runs was used. The amount of $\mathrm{Ni}^{2+}$ adsorbed was optimized numerically to determine the optimum conditions for the adsorption process. The results of the study show that initial $\mathrm{Ni}^{2+}$ concentration of $100 \mathrm{mg} / \mathrm{l} ; \mathrm{pH}$ value of $6.69 ; 5 \mathrm{~g}$ adsorbent dosage and 365.89 minutes contact time were the optimum process conditions for the removal of $18.43 \mathrm{mg} / \mathrm{g}$ of $\mathrm{Ni}^{2+}$ representing $97 \%$ of the maximum predicted adsorption rate. It can be concluded therefore, that water melon rind activated carbon has high adsorption capacity and can be used effectively as adsorbent for the removal of nickel from nickel polluted waste and surface water.
\end{abstract}

Keywords: Adsorption, nickel ion, optimization, response surface methodology, water melon rind

\section{INTRODUCTION}

One of the major environmental problem currently facing many developing countries of the World is the introduction of heavy metals polluted wastewater into the environment $[1,2]$. Heavy metals found in untreated or partially treated industrial wastewater normally discharged into water bodies and soil include nickel $(\mathrm{Ni})$, lead $(\mathrm{Pb})$, mercury $(\mathrm{Hg})$, arsenic (As) and other lethal metals [3] These metals pose both shortterm and long-term danger to both humans and the environment due to their non-biodegradability [4]

One of the heavy metals contained in effluent wastewater that had not received much attention like others is nickel. This is because, unlike other metals, nickel is usually present in the environment in low concentrations and it is used by humans for many different applications; it is even found in some foodstuffs such as vegetables in tolerable concentrations [5]. However, high concentration of nickel in the environment constitutes great danger to human health. High up-take of nickel by humans may lead to lung cancer, nose cancer, larynx cancer, asthma and other related ailments $[5,6]$. Nickel can be found in high concentration in wastewater generated by industries such as electroplating, battery manufacturing, ceramics and glass, metal plating and finishing, printing as well as tanning. There is need, therefore, to properly treat wastewater from these industries to avoid introducing nickel and other lethal metals into the environment.

Removal of heavy metals including nickel from industrial effluents is usually accomplished through conventional methods such as activated carbon adsorption, ion exchange, evaporation, solvent extraction, biosorption, reverse osmosis and electrodialysis [6, 7]. The most effective of these conventional methods is activated carbon adsorption, however; the application of this method by most developing countries in the treatment of wastewater laden with heavy metals is limited by the exorbitant cost of the imported carbon. To optimize the benefit of the activated carbon adsorption method, it is of paramount importance to source for an inexpensive activated carbon that can substitute for, and with 
similar or better adsorptive capacity as the imported commercial grade carbon. In many developing countries, different agricultural wastes such as banana peels, cassava peels, coconut husk, rice bran, corn cob, palm oil empty bunch, fly ash etc. had been experimented with excellent results $[7,8,9,10,11,12]$. However, most of these formulated adsorbents are selective in the removal of trace metals from the targeted effluents. To improve the adsorption efficiency of agricultural wastes activated carbon, it has to be modified chemically or chemically activated. This is because chemical activation of adsorbent improves its adsorption capacity as it increases the number of active binding sites resulting in better metal uptake because of formation of new functional groups due to better ion exchange properties. Of the many agricultural wastes activated carbon experimented as adsorbents, water melon rind had not received much attention. Water melon is a special berry with a hard smooth rind. Water melon rind consists of pectin, citrulline, cellulose, proteins and polymers rich in functional groups such as hydroxyl, amine and carboxylic that are favourable for binding of metal ions $[13,14]$. Kinetic models as well as empirical models such as adsorption isotherms are generally used to determine the efficiency of an adsorbent in removing targeted pollutant from wastewater and other polluted water bodies intended for re-use [15]. However, if the task at hand is purely predictive the aforementioned models need to be augmented with an appropriate optimization technique which is able to identify and evaluate interactive effects between all variables responsible for adsorption. Multivariable statistical experimental design methods that can identify a combination of factors and interactions between wide ranges of variables have been applied by many to reduce cost of research and save valuable time [2, 3]. In most cases, various optimization techniques have been applied in validating the developed statistical experimental designs. For example, the one-factor-at-a-time (OFAT) method was applied in validating experimental design for the removal of heavy metals from aqueous solution using Dowex 50W resin as adsorbent, the technique, however, was found to be too lengthy and time consuming [16]. However, the limitations associated with the OFAT were eliminated by optimizing the same process variables using factorial strategies that employ statistical experimental design with response surface methodology (RSM) $[2,17]$. In the later experiment, the central composite rotatable design (CCRD) was chosen to quantitatively identify the important interactive factors in the process and the results obtained was excellent. In the present study, activated carbon produced from water melon rind (an agricultural waste that currently poses a disposal nuisance) is used as an adsorbent for the selective removal of $\mathrm{Ni}^{2+}$ from a synthetic wastewater. The reaction parameters affecting the performance of the formulated adsorbent as determined from the experimental design were optimized using the response surface methodology (RSM) technique. The experiment was designed using design expert 7.0 (Box Behnken Design (BBD)).

\section{MATERIALS AND METHODS}

\subsection{Materials}

The materials used for the experimental study include fresh water melon rinds collected from a popular fruit market in Oleh, Delta State of Nigeria, PG AA500 absorption spectrophotometer, weighing balance (OHAUS and METTLER PM 4800 Delta Range), stopwatch, muffle furnace, mortar and pestle, $\mathrm{pH}$ meter, laboratory glassware as well as deionized water, nickel (II) trioxonitrate salt, $0.1 \mathrm{M}$ sodium hydroxide solution, $1.0 \mathrm{M}$ zinc chloride and $0.1 \mathrm{M}$ trioxonitrate (V) acid. All chemicals used were of analytical grade.

\subsection{Experimental Procedure}

\subsubsection{Preparation of Watermelon Rinds Activated Carbon and Synthetic Wastewater}

Watermelon Rinds (WR) obtained from a local fruit market (Yanga market in Oleh, Isoko South Local Government Area of Delta State) was washed with tap water before rinsing it twice with distilled water. The thoroughly washed WR was cut into small pieces and dried under sunlight for 7 days before subjecting it to size reduction by crushing using a mortar and pestle and then filtered with a $500 \mu \mathrm{m}$ sieve filter. The filted WR were then washed thoroughly with distilled water to remove any unwanted matter introduced during the crushing process. The washed WR samples were then placed in an oven maintained at $105^{\circ} \mathrm{C}$ for 12 hours for moisture removal; the final moisture content being $1.04 \pm 0.02 \mathrm{wt} \%$. $100 \mathrm{~g}$ of the dried WR was then measured and introduced into the hot zone of the muffle furnace maintained at $380^{\circ} \mathrm{C}$ for 120 minutes. The carbon formed was allowed to cool for 5 hours at room temperature. The oven-dried WR pellets was then reduced to powder using a conventional grinder and sieved through a 100-mesh sieve. 100g each of the carbonized and cooled WR was then activated with 150g 1.0M Zinc chloride following standard method [7, $18]$.

Nickel ion stock solution was prepared from nickel (II) trioxonitrate salt dissolved in deionized water to the 
desired metal concentration following the method employed in an earlier study [19]. 0.1 $\mathrm{M} \mathrm{HNO}_{3}$ and $0.1 \mathrm{M}$ $\mathrm{NaOH}$ solutions was used for the $\mathrm{pH}$ adjustment of the prepared solution.

\subsubsection{Batch Mode Adsorption Studies}

Batch mode adsorption studies were carried out to investigate the effect of four parameters (i.e. $\mathrm{Ni}^{2+}$ concentration, WR dosage, contact time and $\mathrm{pH}$ ) on the removal of nickel from the synthetic wastewater solution. $50 \mathrm{ml}$ of solution containing different concentration of $\mathrm{Ni}^{2+}$ and at different dosages of WR activated carbon and pH values as drawn up by Design Expert 7 (Box Behnken Design), were placed in 250ml capacity conical flasks and left to stand at room temperature. At the end of different pre-determined contact time interval, each flask was thoroughly agitated to ensure proper mixing of the contents before decanting the adsobate from the adsorbent by means of a filter paper. The $\mathrm{pH}$ of each of the samples was adjusted to the desired values specified by the design of experiment by using $0.1 \mathrm{M} \mathrm{HNO}_{3}$ and $\mathrm{NaOH}$ solutions. The filtered samples were then stored in sample bottles labeled according to the respective experimental run prior to analysis. 29 samples obtained from the 29 experimental runs were analyzed using the Atomic Adsorption Spectrophotometer (AAS). The amount of the metal ion sorbed and percentage of removal of metal ion by the biosorbent were calculated using the following equations $[20,21]$

and

$$
q=\frac{V}{M}\left(C_{o}-C_{f}\right)
$$

$$
\% \text { removal }=\left(\frac{C_{o}-C_{f}}{C_{o}}\right) \times 100
$$

Where $\mathrm{q}$ is the amount of metal ion adsorbed by the activated carbon or adsorbent $(\mathrm{mg} / \mathrm{g}), \mathrm{C}_{\mathrm{o}}$ and $\mathrm{C}_{\mathrm{f}}$ are the initial and final metal ion concentrations respectively in the wastewater $(\mathrm{mg} / \mathrm{l}), \mathrm{V}$ is the volume of wastewater used (l) and $M$ is the mass of activated carbon or adsorbent used (g)

\subsection{Experimental Design}

A four variable Box-Behnken design (BBD) for response surface methodology was used to model the combined effect of initial nickel ion concentration (A), pH (B), adsorbent dosage (C) and contact time (D) with an additional one category factor (type of adsorbent (E)), on the percentage nickel removal over three levels since the suspected response of the selected factors is assumed to be quadratic based on experience. The optimum process conditions for the removal of nickel ions from the synthetic wastewater were then studied by means of the response of each variable in the design. The number of experimental runs for the optimization process was determined according to the following equation:

$$
N=K^{2}+K+C_{p}
$$

Where, $\mathrm{K}$ is the number of factors to be optimized and $C_{P}$ is the number of replications at the center point. Using the Design Expert® 7.0 statistical package, 29 experimental runs were obtained. The 29 experimental runs were randomized to maximize the effects of unexplained variability in the observed responses due to extraneous factors with the levels of the independent variables selected based on preliminary experiments. Using the employed statistical design, a second degree polynomial was fitted to the experimental data to estimate the response of the dependent variable and predict the optimal point. The second degree polynomial obtained was of the form:

$$
\begin{aligned}
Y=b_{o}+b_{1} X_{1}+ & b_{2} X_{2}+b_{3} X_{3}+b_{12} X_{1} X_{2}+b_{13} X_{1} X_{3} \\
& +b_{13} X_{1} X_{3}+b_{11} X_{1}^{2}+b_{22} X_{2}^{2} \\
& +b_{33} X_{3}^{2}
\end{aligned}
$$

Where: $Y$ is the predicted response; $\mathrm{X}_{1}, \mathrm{X}_{2}, \mathrm{X}_{3}$ are independent variables; $b_{0}$ is the offset term; $b_{1}, b_{2}, b_{3}$ are linear effects while $b_{11}, b_{22}$ and $b_{33}$ are interactions respectively

\section{RESULTS AND DISCUSSION}

\subsection{Response Surface Model Results}

The results of the batch mode experiment for the removal of $\mathrm{Ni}^{2+}$ from the simulated wastewater using water melon rind activated carbon is shown in Table 1. The independent and dependent variables were analyzed to obtain a regression equation, which is an empirical relationship between the amount of $\mathrm{Ni}^{2+}$ removed and the adsorption variables represented in coded units in order to predict the response under the experimental conditions.

The following regression equation was found to perfectly describe the removal of nickel from the tested solution after subjecting the model to regression analysis and Pareto analysis of variance.

$$
\begin{aligned}
Y=4,0 A+0.017 & +0.043 C+4.10 D+0.0 D \\
& +0.028 A B-0.019 A C-3.77 A D \\
& +0.022 B C-0.05 B D-0.041 C D \\
& +0.024 A^{2}+0.017 B^{2}-0.062 C^{2} \\
& +2.743 D^{2}+3.43
\end{aligned}
$$


Table 1: Results of Box Behnken batch mode experimental design for the removal of $\mathrm{Ni}^{2+}$ from wastewater using water melon rind activated carbon for Block 1

\begin{tabular}{|c|c|c|c|c|c|c|}
\hline \multirow{2}{*}{ Standard order } & \multirow{2}{*}{ Run } & \multicolumn{4}{|c|}{ Independent Variables } & \multirow{2}{*}{$\begin{array}{c}\text { Response } \\
\mathrm{Ni}^{2+} \text { Removal (\%) }\end{array}$} \\
\hline & & $\mathrm{A}(\mathrm{mg} / \mathrm{l})$ & $\mathrm{B}$ & C (minutes) & $\mathrm{D}(\mathrm{g} / \mathrm{l})$ & \\
\hline 21 & 1 & 52.5 & 2 & 362.5 & 5 & 49.8 \\
\hline 14 & 2 & 52.5 & 7 & 5 & 15 & 16.6 \\
\hline 7 & 3 & 52.5 & 4.5 & 5 & 25 & 10.0 \\
\hline 29 & 4 & 52.5 & 4.5 & 362.5 & 15 & 17.1 \\
\hline 16 & 5 & 52.5 & 7 & 720 & 15 & 17.1 \\
\hline 6 & 6 & 52.5 & 4.5 & 720 & 5 & 50.0 \\
\hline 26 & 7 & 52.5 & 4.5 & 362.5 & 15 & 17.1 \\
\hline 23 & 8 & 52.5 & 2 & 362.5 & 25 & 10.2 \\
\hline 10 & 9 & 100 & 4.5 & 362.5 & 5 & 97.0 \\
\hline 13 & 10 & 52.5 & 2 & 5 & 15 & 16.7 \\
\hline 27 & 11 & 52.5 & 4.5 & 362.5 & 15 & 16.7 \\
\hline 15 & 12 & 52.5 & 2 & 720 & 15 & 16.7 \\
\hline 28 & 13 & 52.5 & 4.5 & 362.5 & 15 & 17.1 \\
\hline 19 & 14 & 5 & 4.5 & 720 & 15 & 1.2 \\
\hline 4 & 15 & 100 & 7 & 362.5 & 15 & 32.5 \\
\hline 11 & 16 & 5 & 4.5 & 362.5 & 25 & 0.8 \\
\hline 9 & 17 & 5 & 4.5 & 362.5 & 5 & 4.7 \\
\hline 17 & 18 & 5 & 4.5 & 5 & 15 & 0.6 \\
\hline 5 & 19 & 52.5 & 4.5 & 5 & 5 & 48.9 \\
\hline 18 & 20 & 100 & 4.5 & 5 & 15 & 32.0 \\
\hline 3 & 21 & 5 & 7 & 362.5 & 15 & 1.4 \\
\hline 8 & 22 & 52.5 & 4.5 & 720 & 25 & 10.2 \\
\hline 1 & 23 & 5 & 2 & 362.5 & 15 & 1.6 \\
\hline 2 & 24 & 100 & 2 & 362.5 & 15 & 32.2 \\
\hline 20 & 25 & 100 & 4.5 & 720 & 15 & 32.2 \\
\hline 22 & 26 & 52.5 & 7 & 362.5 & 5 & 50.6 \\
\hline 24 & 27 & 52.5 & 7 & 362.5 & 25 & 10.0 \\
\hline 25 & 28 & 52.5 & 4.5 & 362.5 & 15 & 16.7 \\
\hline 12 & 29 & 100 & 4.5 & 362.5 & 25 & 65.2 \\
\hline
\end{tabular}

The surface response analysis is aimed at developing a statistical model that will show the combined effects of the independent variables investigated on the response or percentage $\mathrm{Ni}^{2+}$ removal from wastewater. To achieve this objective, the results shown in Table1 was used as basis for further analysis using the one-way analysis of variance (ANOVA). The result of these analyses are shown in Table 2.

The significant lack-of-fit for the model is $p=0.0781$ indicating that the quadratic model is valid for this study and that the number of experiments performed were sufficient to determine the effect of the independent variables on the percentage $\mathrm{Ni}^{2+}$ removal from wastewater. It is therefore, an indication that the predictive knowledge of the model is statistically sufficient.
Table 2 Summary of $p$-value for the surface response model analysis for the percentage $\mathrm{Ni}^{2+}$ removal from synthetic wastewater (full quadratic model)

\begin{tabular}{ll}
\hline Regression term & P - value \\
\hline Initial nickel concentration (A) & 0.7323 \\
pH (B) & 0.7447 \\
Time (C) & 0.8778 \\
Adsorbent dosage (D) & 0.001 \\
B X A (Interactive) & 0.9618 \\
B X D (Interactive) & 0.9312 \\
B X C (Interactive) & 0.9693 \\
D X C (Interactive) & 0.9422 \\
R $^{2} \%$ & 96.5 \\
Lack-of-fit (LOFT) value & 0.0781 \\
\hline
\end{tabular}

\subsection{Sensitivity Analysis}

The perturbation plot shown in Figure 1 compares the effect of all the independent variables at a particular point in the design space. The response is plotted by 
changing only one variable over its range while holding the other variables constant. A steep slope or curvature in a variable shows that the response is sensitive to that particular variable. A relatively flat line shows that the response is insensitive to changes in that particular variable. The perturbation plot is therefore, a way of determining the variable that most affects the response (i.e. the adsorption process). Figure 1 shows the extent of significance of initial nickel concentration (A), $\mathrm{pH}$ (B), Contact time (C) and adsorbent dosage (D) on the response $\left(\mathrm{Ni}^{2+}\right.$ removal). Adsorbent dosage is observed to be the most significance among all the variables.

\subsection{Effect of Process Variables on the Removal of Nickel (II) Ions from Solution}

The effects of the various independent variables on the removal efficiency of the $\mathrm{Ni}^{2+}$ pollutant from the wastewater are represented graphically below by 3 dimensional (3D) response surfaces and corresponding contour plots. The response surface and contour plots give a vivid picture of the relative effects of any two of the variables when the remaining variables were kept constant.

\subsubsection{Combined effect of Initial Nickel Concentration and pH}

The combined effects of initial nickel concentration and $\mathrm{pH}$ of the solution on the total nickel removed from the simulated wastewater at constant time and adsorbent dosage is shown in Figure 2. An increase in the initial nickel concentration with $\mathrm{pH}$ resulted in an increase in the total amount of nickel ion removed from solution. Initial nickel ion concentration in solution is a significant factor on the adsorption of nickel ions onto watermelon rind activated carbon than the $\mathrm{pH}$. The low, non-significant interactive effect $(p=0.9618)$ between these two variables can be seen from the plane shape of the response surface plot. However, the little distortion experienced in the shape as the initial nickel ion concentration increases may be due to the availability of additional nickel ions present in solution ready to be adsorbed unto the adsorbent surface, since an increase in the concentration of nickel ion in solution implies a corresponding increase in the number of nickel ions present in the solution, thus leading to rapid uptake of more ions from the solution [22]. Though, the effect of $\mathrm{pH}$ as a single variable on $\mathrm{Ni}^{2+}$ removal efficiency from the wastewater is nonsignificant as shown in Table 2, it can be seen from Figure 2 that the amount of nickel adsorbed increases as the $\mathrm{pH}$ increases. This may be as a result of the reduced competition between the hydronium ion and nickel ion in the solution for the adsorbent surface sites as a result of increased $\mathrm{pH}$ thereby reducing the positive surface charge on the adsorbent leading to lower electrostatic repulsion between the surface and the metal ions. This phenomenon had been found to be responsible for high metal ions removal from solution at high $\mathrm{pH}$ [4]

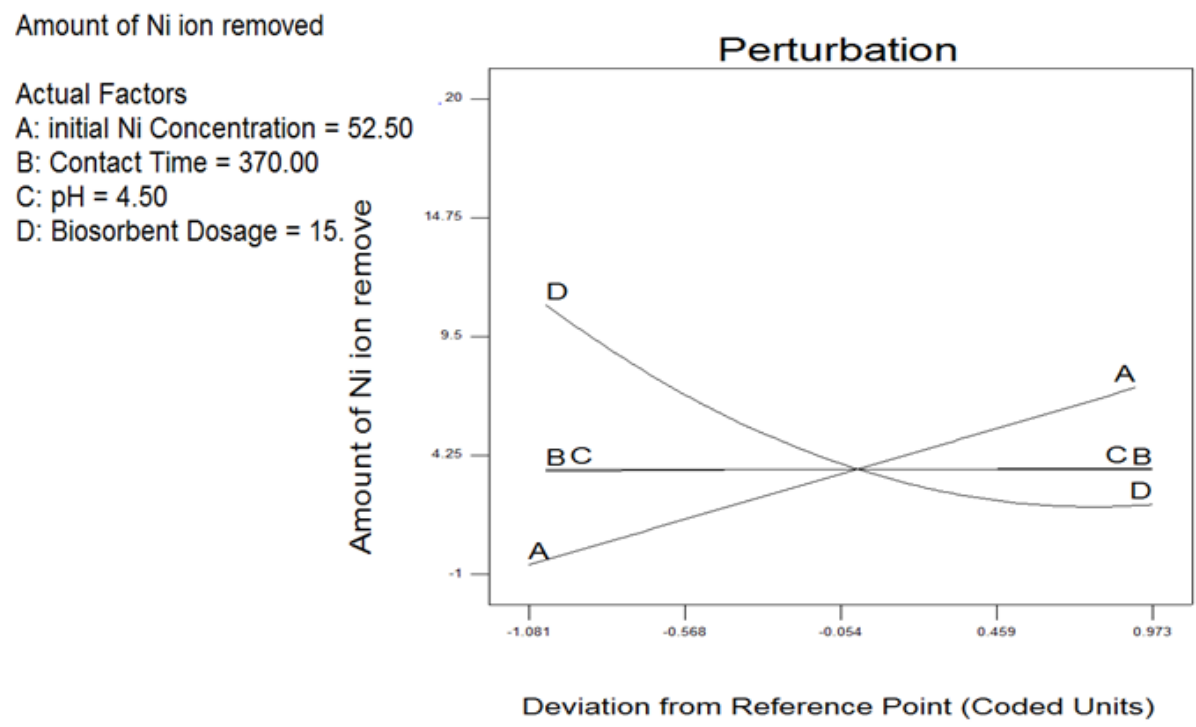

Figure 1 Perturbation plot for the independent variables - initial nickel concentration $(A), p H$

(B), Contact time (C) and adsorbent dosage (D) 


\subsubsection{Combined effect of Initial Nickel Concentration and Contact Time}

Figure 3 shows the effect of the interaction between initial concentration and contact time on the response surface for total nickel ion removed from solution at constant adsorbent dosage and $\mathrm{pH}$ of solution. The combined effect of these variables have no significant effect ( $p=0.9693$ ) on the removal of nickel ion from solution as can be observed from Table 2. It can be seen from the plots, however, that nickel ion removal increases significantly with increasing initial nickel ion concentration in solution. This may be as a result of the high base solution $\mathrm{pH}$ associated with high initial metal ions concentration of the simulated wastewater, despite this, however, it is observed that increase in contact time between the adsorbent and nickel solution has little effect on the total nickel ion removed at the onset of the adsorption process. This low initial nickel ion removal was as a result of large numbers of vacant

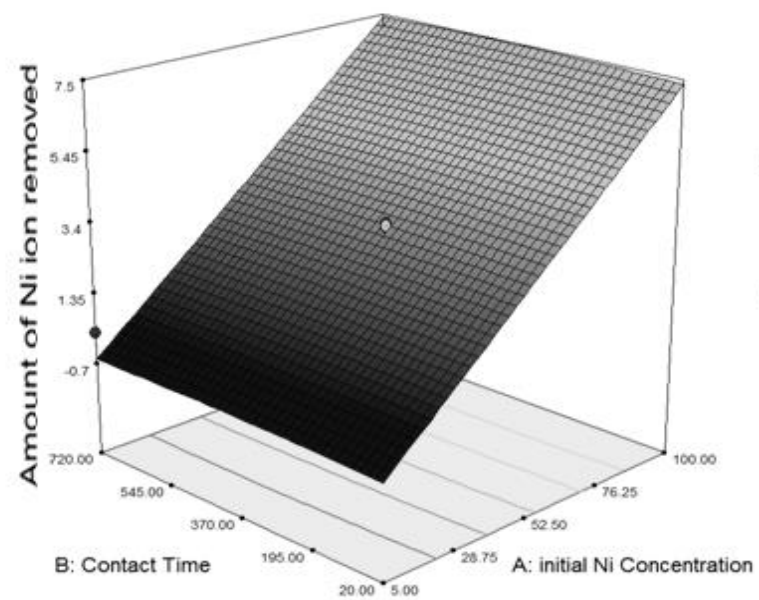

surface sites initially available for adsorption. As adsorption progresses, the repulsive forces between the adsorbate molecules on the solid surface and in the bulk phase becomes higher requiring more time to fill the remaining vacant active sites on the surface of the adsorbent [22]. This explains why it took more than 360 minutes contact time for the removal of about $97 \%$ of nickel ions from the solution.

\subsubsection{Combined effect of Initial Nickel Concentration and Adsorbent Dosage}

The response surface and corresponding contour plots presented in Figure 4 demonstrates the combined effects of nickel ion initial concentration and adsorbent dosage on the nickel ion removal from the simulated wastewater. As shown in Table 2, the combined effects of these variables is highly significant $(p=0.0001)$.

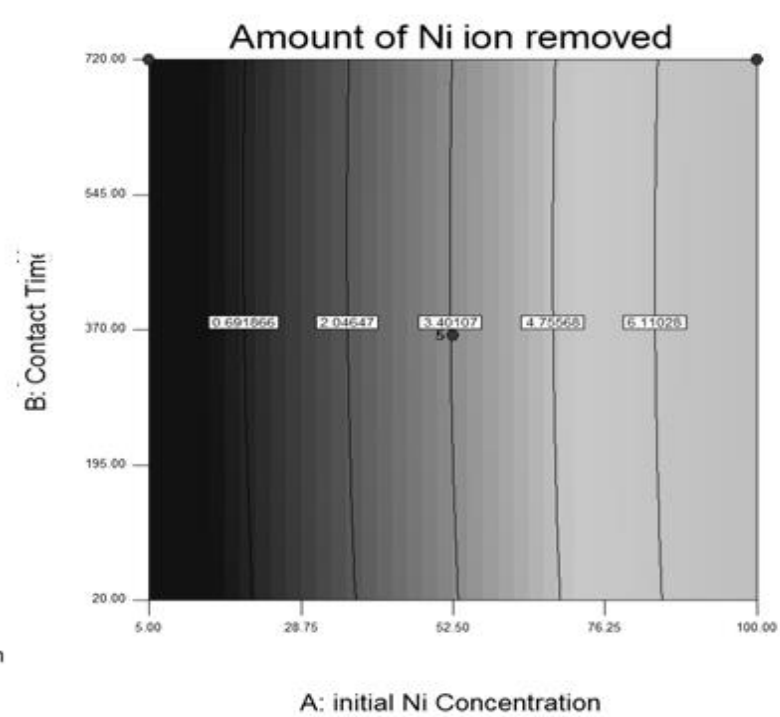

Figure 2 Three dimensional (3D) response surface plot and the corresponding contour plot showing the effects of initial nickel ion concentration and $p H$ of solution on total nickel ion removal.
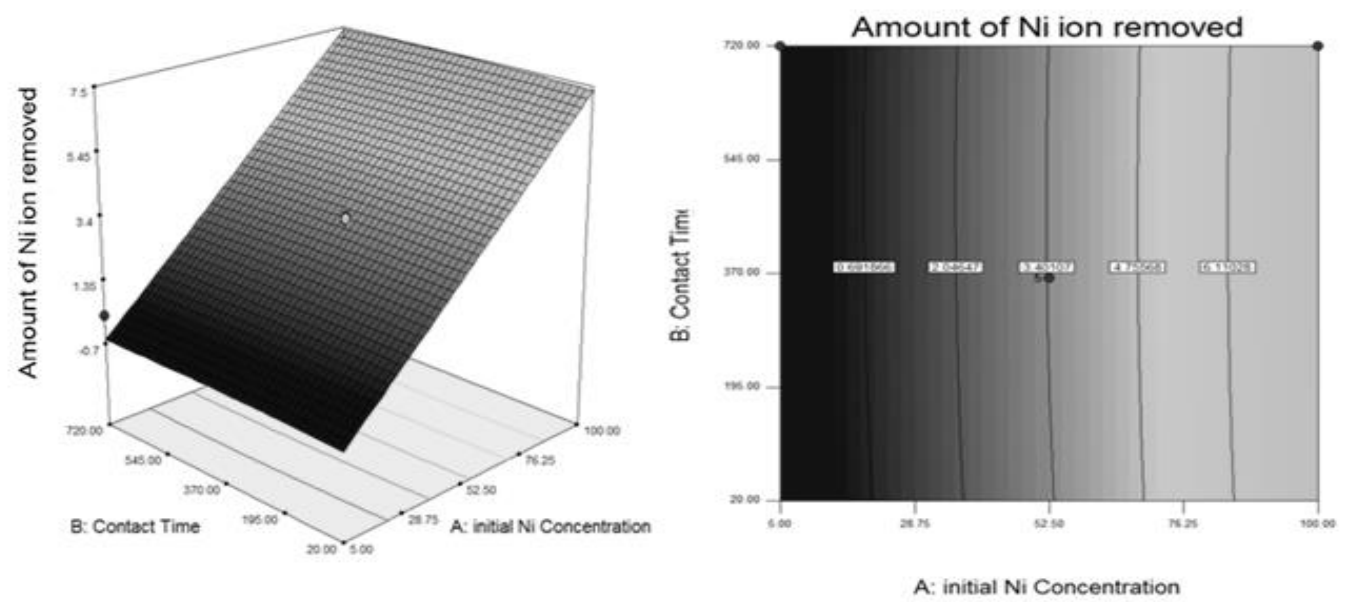

Figure 3: Three dimensional (3D) response surface plot and the corresponding contour plot showing the effects of initial nickel ion concentration and contact time of solution on total nickel ion removal. 

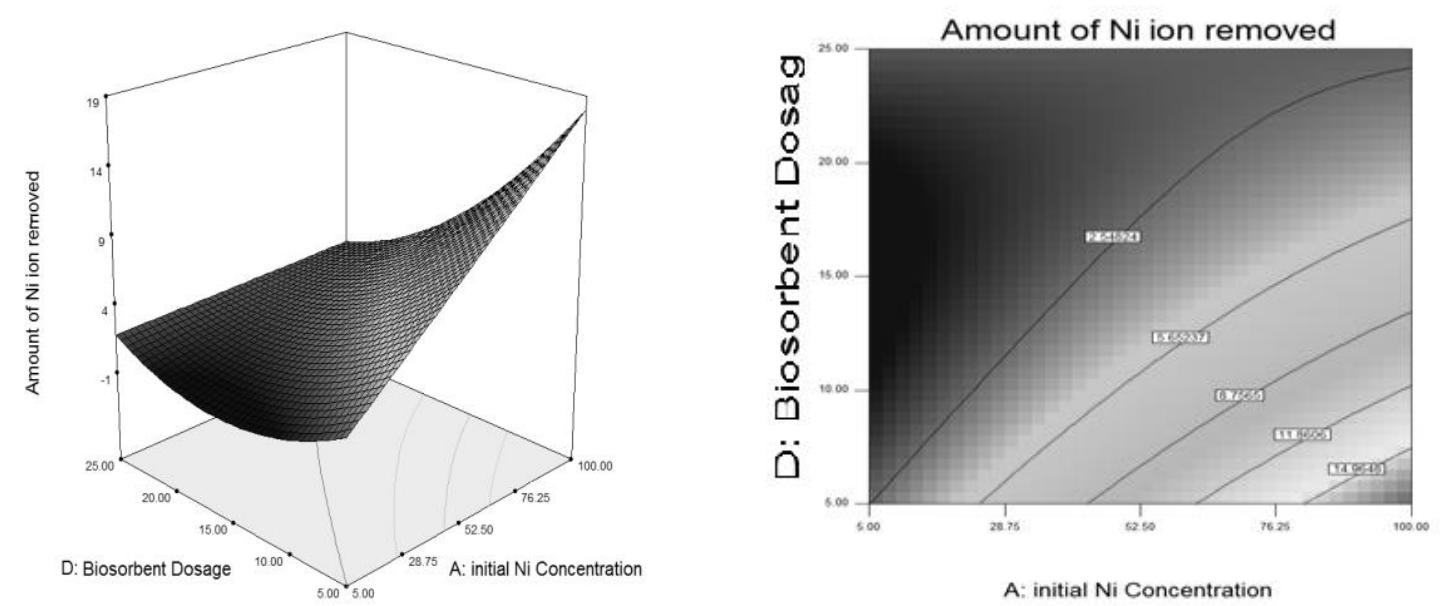

Figure 4: Three dimensional (3D) response surface plot and the corresponding contour plot showing, the effects of initial $\mathrm{Ni}^{2+}$ concentration and adsorbent dose on total nickel ion removal.

Increasing initial nickel concentration in solution greatly affects the sorption of nickel ions onto the adsorbent surface pores. Increasing adsorbent dosage beyond $25 \mathrm{~g} / \mathrm{l}$ at constant $\mathrm{pH}$ and contact time has little effect on nickel ion removal from solution. This may be as a result of oversaturation of available adsorption sites from the increased adsorbent dose thereby reducing the adsorption density $[2,19]$

\subsubsection{Combined effect of $p H$ and Contact Time}

Figure 5 shows the combined effect of contact time and $\mathrm{pH}$ on the response surface for total nickel ion removed from solution at constant adsorbent dosage and initial nickel ion concentration. The interactive effect is nonsignificant $(p=0.9693)$. Despite the non-significant effects of these variables when combined, they were used as basis of establishing the optimum conditions for the study. The centre point of Figure 5 gives the values of contact time and $\mathrm{pH}$ that may be combined with the remaining variables to obtain optimal conditions necessary for effective $\mathrm{Ni}^{2+}$ removal from the simulated solution using the prepared WR activated carbon. These conditions were found to be 362.5

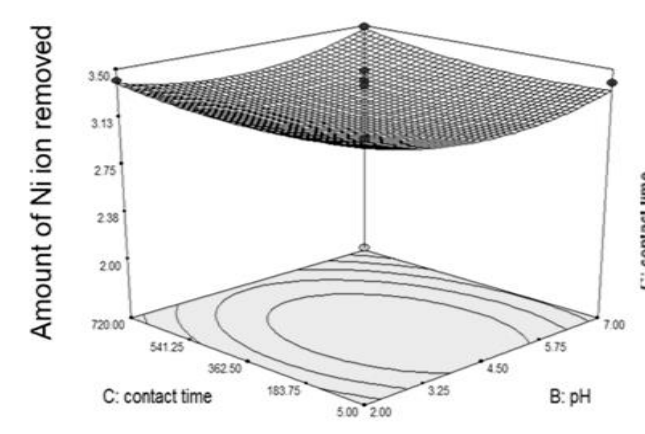

minutes and a $\mathrm{pH}$ of 4.5 respectively. Any further increase in both the contact time and $\mathrm{pH}$ led to reduction in the adsorption of nickel ions from the solution. These conditions were used for the numerical optimization to determine the optimal factors required for maximum removal of $\mathrm{Ni}^{2+}$ from the simulated solution following the method employed by earlier workers [23].

\subsubsection{Combined effect of pH and Adsorbent Dosage}

Figure 6 show the effect of the interaction between $\mathrm{pH}$ and adsorbent dosage on the response surface for total nickel ion removed from solution at constant contact time and initial $\mathrm{Ni}^{2+}$ concentration of the simulated wastewater. The interaction had no significant effect ( $p$ $=0.9312$ ) on the removal of nickel ion from solution. The maximum $\mathrm{Ni}^{2+}$ adsorbed was $3.17 \mathrm{mg} / \mathrm{g}$ corresponding to only $17.1 \%$ at a solution $\mathrm{pH}$ of 4.5 and adsorbent dosage of $15 \mathrm{~g} / \mathrm{l}$. From the plots, we can see that the singular effect of increasing $\mathrm{pH}$ or adsorbent dosage has no effect on the response at the prevailing conditions.

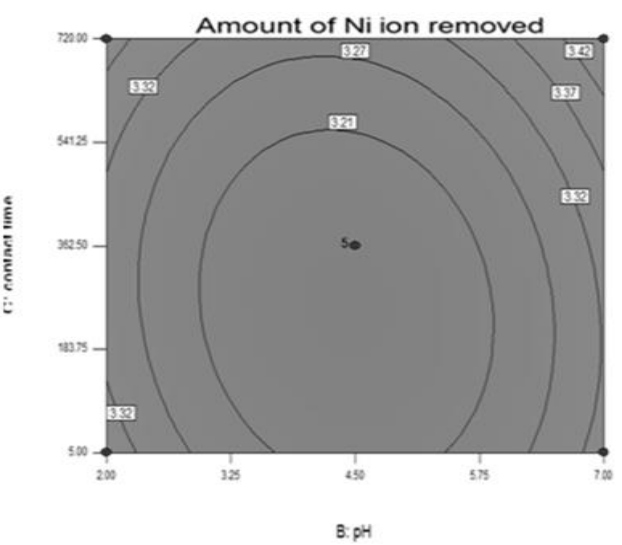

Figure 5: Three dimensional (3D) and the corresponding contour plot showing the effects of contact time and pH of solution on total nickel ion removal. 

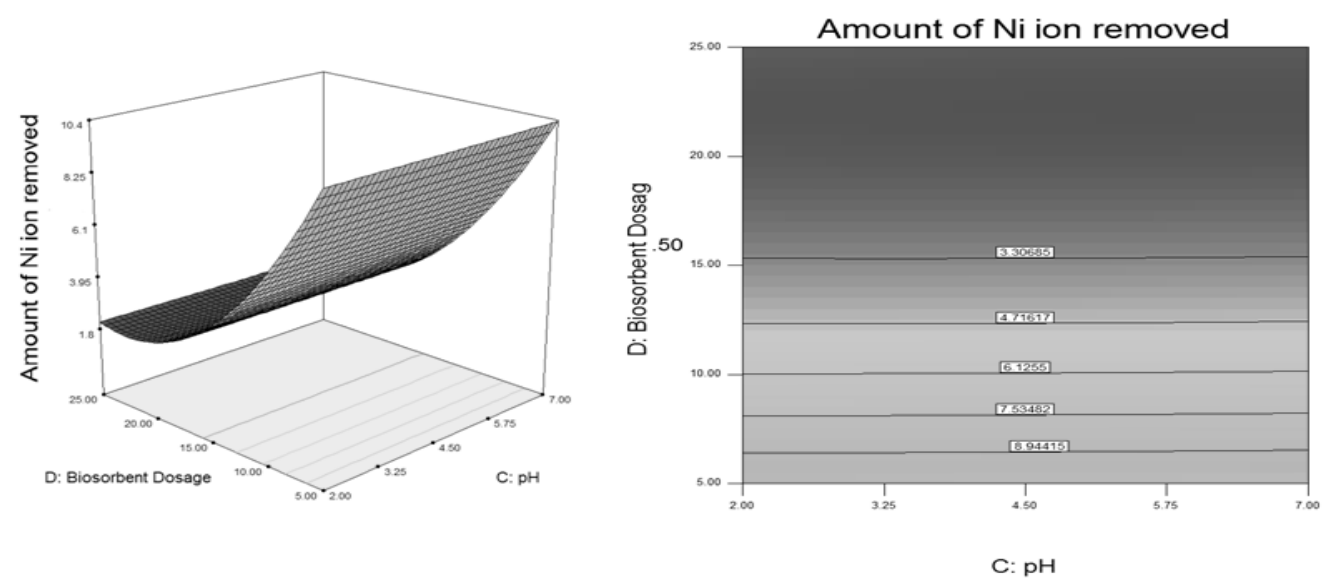

Figure 6: Response surface plot and the corresponding contour plot showing the effects of adsorbent dose and pH of solution on total nickel ion removal

\section{CONCLUSION}

In this study, a three level Box Behnken response surface statistical methodology was utilized in the quantitative study of adsorption of nickel from a simulated aqueous solution. The results show that adsorbent dosage play a major role in the adsorption of nickel from the investigated wastewater, while other variables such as initial nickel ion concentration, $\mathrm{pH}$, and contact time, though not statistically significant are major contributors. The experimental results illustrated in the three dimensional (3D) plots show that there was a clearly defined optimum condition for the removal of $\mathrm{Ni}^{2+}$ from wastewater using watermelon rind activated carbon. From this study, it had been established that response surface methodology (RSM) is a veritable cost saving tool in optimizing adsorption process parameters.

\section{REFERENCES}

[1] Cavaco S. A., Fernandes S, Quina M. M. and Ferrera L.M. Removal of chromium from electroplating industry effluents by ion exchange resins, J. Hazard Mater. Vol. 144. pp. 634, 2007.

[2] Hamdzah M, Ujang Z, Nasef M. M, Hadibarata T, Olsson G, Hassan $\mathrm{H}$ and Rusli N. M Optimization of Zinc (II) and Lead (II) on Dowex 50W resin using a response surface methodology approach, Journal of Environmental Science and Technology, Vol. 6 Number 3. pp. 106-118, 2013.

[3] Kalantari K., Ahmad M. B., Mansoumi H.R.F., Khandanlou R. Rapid adsorption of heavy metals $\mathrm{Fe}_{3} \mathrm{O}_{4} /$ Talc nano composite and optimization study using response surface, International Journal of Molecular Sciences 15. pp. 12913 12920, 2014

[4] Umpuch C, Bunmanan N. Kueasing U, and Kaewsan P. Adsorption of Nickel from Synthetic Solution using Luffa Charcoal, International Journal of Environmental, Chemical, Ecological, Geological and Geophysical Engineering, Vol. 5, Number 9. pp. 81-92, 2011.

[5] Lenntech B. V. Chemical properties, health and environmental effects of nickel, www.lenntech.com/periodic/elements/ni.htm, 2016. Assessed 13/01/16

[6] Dhokpande S.R, Kaware J.P and Kulkarni S.J. Research for removal of nickel from wastewater A review, International Journal of Science, Engineering and Technology Research, Vol. 2, Number 12. pp. 6, 2013

[7] Oghenejoboh K. M; Otuagoma S. O. and Ohimor E.O. Application of cassava peels activated carbon in the treatment of oil refinery wastewater - A comparative analysis, Journal of Ecological Engineering, Vol. 17, Number 2. pp. 52 - 57, 2016

[8] Rangaraj S, Moon S. H, Sivabalan, R Aranbindoo R. and Murugesan V. Agricultural soil waste for the removal of phenol from water and wastewater by palm seed coat activated carbon, J. Waste Management, Vol. 22. pp. 543-545, 2002.

[9] Sarka M and Acharya K. P. Use of fly ash for the removal of phenol and its analogues from contaminated water, Waste Manage, Vol. 26. pp. 559-561, 2006.

[10] Hameed B. H and Tan I. A. W. Adsorption isotherm, kinetic modeling and mechanism of 2, 4, 6-trichlorophenol on coconut husk-based activated carbon, Chem. Eng. J. Vol. 144. pp. 235237, 2008.

[11] Chukwuedo M. E and Okieimen F. E. Enhanced metal adsorption by groundnut husks modified with citric acid, J. Chem. Soc. Nigeria, Vol. 33, Number 2. pp. 50-51, 2008.

Vol. 37, No. 3, July, 2018 
[12] Alinnor I. J and Nwachukwu M. A. Adsorption of phenol on surface-modified cassava peel from its aqueous solution, International Journal of Environmental Science, Management and Engineering, Vol. 1, Number 2. pp. 8-74, 2012.

[13] Jayaprakasha G. B., Chidambara M. K. N and Patil B. S. Rapid HPLC-UV method for quantification of 1-Citrulline in water melon and its potential role on smooth muscle relaxation markers, Food Chem, Vol. 127. pp. 241, 2011.

[14] Ohwonowho E. M. Biosorption of heavy metals from synthetic wastewater using water melon rind, Unpublished B. Eng. Project report, Department of Chemical Engineering, Delta State University, Abraka. pp. 15-35, 2015.

[15] Julian C., McCabe, Smith P., Warren L., Harriott Unit operations of Chemical Engineering", $7^{\text {th }}$ Edition. pp. 836-837, 2005.

[16] Pehlivan E. and Altun T. The study of various parameters affecting the exchange of $\mathrm{Cu}^{2+}, \mathrm{Zn}^{2+}$, $\mathrm{Ni}^{2+}, \mathrm{Cd}^{2+}$ and $\mathrm{Pb}^{2+}$ from aqueous solution on Dowex 50W synthetic resin, J. Hazard. Mater. Vol. 134. pp. 149-152, 2006.

[17] Garg U. K, Kaur M. P., Garg V. K. and Sud D. Removal of nickel (II) from aqueous solution by adsorption on agricultural waste biomass using a response surface methodological approach, Bioresour. Technol. Vol. 99. pp. 1325-1327, 2008.
[18] Awoyale A. A; Eloka-Eboka A. C and Odubiyi A. O. (Production and experimental efficiency of activated carbon from local waste bamboo for wastewater treatment" International Journal of Engineering and Applied Sciences, Vol. 3, Number 2. pp. 8-10, 2012.

[19] Lakshmipathy R, Sarada N. C. Application of watermelon rind as sorbent for removal of nickel and colbalt from aqueous solution, International Journal of Mineral Processing Vol. 122. pp. 63-65, 2013.

[20] Oghenejoboh K. M, Abowei M.F.N and Puyate Y. T. Sorption mechanism of Nigerian crude petroleum into soil medium, Pollution Research, Vol. 27, Number 1,. pp. 7-8, 2008.

[21] Saed K, Johari M., Noor M. M and Yusuf B. Sugarcane bagasse as an adsorbent for dye removal Journal of Industrial Pollution Control, Vol. 21,. pp. 3, 2005.

[22] Saueprasearsit P, Nuanjaraen M. and Chinlapa M. 'Biosorption of $\mathrm{Pb}^{2+}$ by Luffa cylindricalfiber" Environmental Research Journal, Vol. 4, Number 1. pp. 157-166, 2010.

[23] Maran P. M and Manikandan S Response surface modeling and optimization of process parameters for aqueous extraction of pigments from prickly pear (opuntia ficus-indica) fruit, Dye and Pigments, Vol. 95, Number 3,. pp. 465-469, 2012. 